\title{
Pathological findings after right lung transplantation in a patient with fibrosing alveolitis
}

\author{
K. B. SHILKIN AND LYNNE REID \\ From the Department of Morbid Anatomy, King's College Hospital Medical School, London, and the \\ Institute of Diseases of the Chest, Brompton Hospital, London
}

SYNOPSIS The pathological findings in a patient who died two months after right lung transplantation for fibrosing alveolitis are reported. The cause of death was haemoptysis, due to penetrating ulceration causing a fistula between the surface of the cartilagenous part of the main bronchus of ${ }^{\infty}$ the donor lung and the right upper lobe pulmonary artery. The opening in the donor bronchus was $\underset{\perp}{ }$ immediately distal to the line of the bronchial anastomosis and through an actively inflamed area. 윽 Other parts of the donor bronchus had microscopic changes suggesting ischaemia, emphasizing that inadequacy of blood supply to the donor extrapulmonary bronchus is one of the most serious hazards of lung transplantation. Within the lung, histological features of rejection were mild and $\underset{\oplus}{\infty}$ there was minimal evidence of infection. Another question raised by this case is whether the donor lung was in the process of developing the original disease, evidence for which was sought electron $\oplus$ microscopically but was not proven.

Lung transplantation gives rise to three main types of problem, namely, (1) anatomical, particularly the maintenance of an adequate blood supply to the bronchial stump of the donor lung; (2) immunological, including the hazards of rejection and its concomitants of immunosuppression and infection; and (3) recrudescence of the underlying disease process which is especially pertinent in fibrosing alveolitis where the possibility exists that the primary disease may develop in the new lung.

Hugh-Jones, Macarthur, Cullum, Mason, Crosbie, Hutchison, Winterton, Smith, Mason, and Smith (1971) reported the transplantation of a single lung to a patient with fibrosing alveolitis which produced dramatic improvement in lung function during the two months that the patient survived. Those pathological findings relevant in establishing the mode of death, the nature and severity of the disease in the resected and residual lungs, and the changes that developed in the donor lung are reported here.

\section{Case Report}

Details of the patient's clinical record have previously been reported (Hugh-Jones et al, 1971). He had finger clubbing from the age of 15 years but did not develop breathlessness until he was 30 when it became progressively worse. After investigation, Received for publication 18 May 1972. including lung biopsy, the diagnosis of cryptogenic fibrosing alveolitis was made. His shortness of breath was sufficiently severe to require continuous oxygen, even at complete rest. He was 40 years of age at the time of right lung transplantation. The donor lung was removed from a 16-year-old boy who died suddenly of cerebral haemorrhage. Before its removal the lung had been ventilated for a total of 15 hours, $\frac{?}{0}$ the donor having been certified cerebrally dead for $:$ the last 12 hours. When the anastomoses of the left atrium, pulmonary artery, and bronchus were $\delta$ satisfactorily completed and blood flow re-established $₹$ the warm ischaemia time of the donor lung had been 음 59 minutes.

By the fourth postoperative day the patient was able to walk and was not breathless. Immuno-

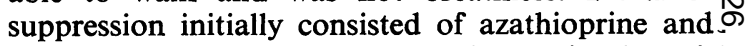
prednisone supplemented by actinomycin $\mathbf{C}$ and, $\widetilde{O}$ later, antilymphocytic globulin. His clinical course $\mathbb{W}^{-}$ fluctuated and several of his ill periods were thought $\sigma$ to be related to episodes of incipient rejection. From day 35 to his death he had a fever which, although treated by antibiotics, could not be established as due $\stackrel{?}{+}$ to infection. Terminally he had three episodes of 0 haemoptysis, one of $30 \mathrm{ml} 24$ hours before he died, another, more severe, which led to unconsciousness $\stackrel{\mathbb{D}}{\circ}$ 13 hours before his death, and finally a massive, fatal $\mathbb{D}$ haemoptysis. 


\section{NECROPSY FINDINGS}

The major findings were in the lungs. Most other organs were normal, or had only minor changes; noteworthy was the presence of clubbing, osteoporosis, adrenal cortical atrophy and, according to the method of Fulton, Hutchinson, and Jones (1952), mild right ventricular hypertrophy (right ventricle $65.6 \mathrm{~g}$; ratio of left ventricle plus septum to right ventricle 1.92 ).

The residual lung, the left, was firm and nodular without pleural adhesions. On the right side, the pleura of the donor lung had a smooth external surface, thickened and adherent only at the site of the thoracotomy incision. Filling the trachea there was a large, recently formed blood clot, which extended into and occluded both major bronchi. The findings after fixation are described below.

\section{PATHOLOGICAL STUDIES}

The operatively resected lung was stored for some days at $-20^{\circ} \mathrm{C}$, thawed and the arteries injected with barium-gelatin suspension (Hislop and Reid, 1970). The lung was then fixed by intratracheal distension with buffered formol-saline and subsequently cut and examined. At necropsy the lungs and heart were removed en bloc and fixed in a similar manner so that dissection of the bronchial stump and adjacent structures could be more precisely undertaken. From numerous blocks of all three lungs routine $5 \mu \mathrm{m}$ sections were stained by these methods: Ehrlich's haematoxylin and eosin, Verhoef-van Giesen, alcian blue-periodic acid Schiff sequence, Gordon and Sweet's reticulin, Perl's Prussian blue reaction, Martius scarlet-blue, phosphotungstic acidhaematoxylin, Gram and Unna-Pappenheim's methyl green-pyronin. Immediately after certification of death, lung puncture biopsy was carried out to obtain tissue for electron microscopy but, unfortunately, the material obtained from the donor lung included only the wall of a large airway. At necropsy further specimens for electron microscopy were placed in glutaraldehyde, and, while not as well preserved, did make possible some evaluation of the lungs.

\section{Resected right lung}

The right lung at the time of formalin inflation was small, its surface had a 'hob-nail' appearance but pleural adhesions, except across the fissures were absent. The arteriogram showed normal filling of the main axial arteries and large side branches, except in the anterior segment of the upper lobe where the appearance was suggestive of a thrombus. In all other areas intralobular vascularity was reduced. Examination of the sliced lung revealed a widespread honeycomb pattern. On light microscopy the disruption of lung architecture was confirmed, the honeycomb spaces being lined either by fibrous tissue or bronchial-type epithelium. There was sparse chronic inflammatory cell infiltration. The fragments for electron microscopy proved to be from aregion where alveolar structure was no longer apparent. All these features confirm that the patient was suffering from an advanced stage of cryptogenic fibrosing alveolitis (synonyms are diffuse interstitial pulmonary fibrosis, Hamman-Rich syndrome, desquamative histiocytosis) mainly of grades 4 and 5 (Livingstone, Lewis, Jefferson, and Reid, 1964).

\section{Residual left lung removed at necropsy}

This had virtually the same changes as the resected right lung with the additional effects of aspiration of a considerable amount of blood. There was no evidence microscopically of cytomegalovirus or other infection.

\section{Donor right lung}

Both on its pleural and cut surfaces, particularly in the posterior and inferior regions, it was mottled with alternating purplish-red and pale areas of approximately $1 \mathrm{~cm}$. The large airways were filled with blood clot. While the general pulmonary architecture was intact, the normal spongy appearance of lung was not obvious and the lung felt rubbery. The pulmonary and left atrial anastomoses were intact. After removal of the clot from the major airways the tracheal and bronchial mucosa proximal to the bronchial anastomosis was found to be normal; distal to it in the cartilagenous part of the bronchus there was ulceration and tissue disintegration for $1.8 \mathrm{~cm}$. Projecting fragments of cartilage and loose sutures were evident in the debris. The ulcer extended through both the bronchial and the pulmonary artery walls with an opening $2 \mathrm{~mm}$ in diameter into the lumen of the right upper lobe pulmonary artery (Fig. 1). The membranous part of the donor bronchial mucosa, including the anastomosis, appeared intact.

\section{LIGHT MICROSCOPY}

To the line of its anastomosis the recipient bronchus was virtually normal. Beyond this the donor bronchial tissue was severely damaged with loss of specialized structures, surface ulceration, fibrosis, and moderate round cell inflammatory infiltration. Some small arteries had the lumina occluded by fibrous tissue. The region of the bronchopulmonary artery fistula was necrotic and there was much associated active inflammation. In this necrotic zone many mixed bacilli and cocci were observed in Gramstained sections. Plates of cartilage immediately below the bronchial anastomotic line and judged to be extrapulmonary were necrotic whereas those 


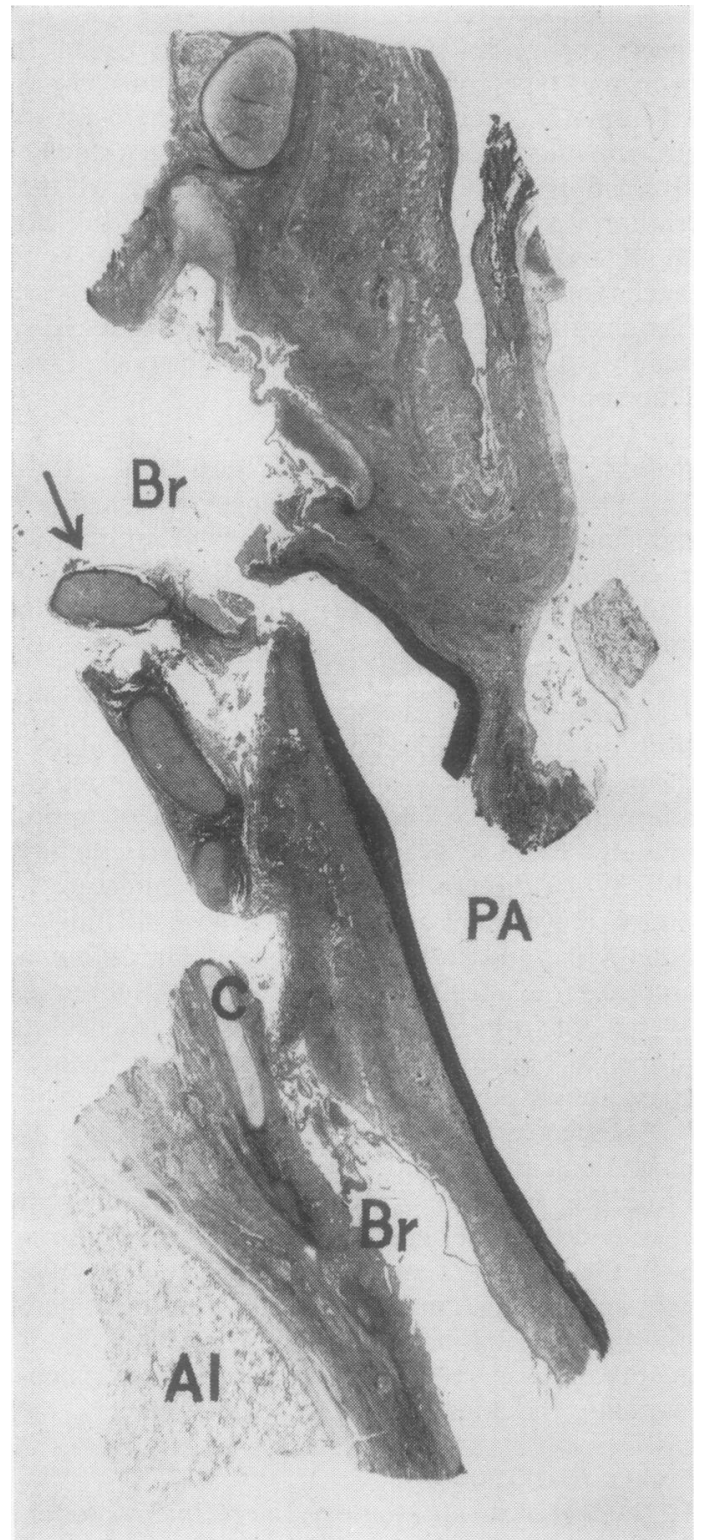

Fig. 1 Low-power photomicrograph of the ulcer eroding bronchial wall (Br), and pulmonary artery (PA) that caused the fatal haemoptysis. Cartilage in the extrapulmonary donor bronchus is acellular and projecting into the base of the bronchial ulcer (at arrow). Cartilage (C) within the lung $(\mathrm{Al}=$ alveoli) still stains. $\mathrm{H} \& \mathrm{E}$ $\times 4$.

within the lung were viable having deeply staining nuclei. These observations support the contention that the extrapulmonary part of the donor bronchus had sustained a degree of ischaemia, leading to $\stackrel{0}{\vec{\sigma}}$ necrosis with perforation into a pulmonary artery at one point.

A variety of changes were seen throughout the lung. Other than those filled with blood, most alveoli were virtually normal. Some were lined by plump cells while others contained macrophages, eosinophilic material or fibrin, organization of which was sometimes well advanced. Scattered throughout the lung there was a mild or moderate inflammatory $\vec{\circ}$ cellular reaction mainly within alveolar walls where $\overrightarrow{\vec{\omega}}$ lymphocytes, plasma cells, and other mononuclear $\stackrel{\rho}{\sigma}$ cells formed small accumulations. Similar collections 응 were found in the submucosal layers of the small airways, the connective tissue septa and the adventi- on tia of large vessels. Less frequently a region of denser $o$ infiltration was found. Some of these cells were $\underset{A}{A}$ pyroninophilic. No difference was seen either between 의 lobes or between subpleural and central regions. The intralobular arteries and veins were widely patent $\longrightarrow$ and showed no endothelial changes or inflammation. There was no overall increase in connective tissue. Scattered through the donor lung, on an average at least one per medium-power field, were cells containing the cytomegalovirus.

\section{ELECTRON MICROSCOPY}

The bronchial submucosal gland revealed normal cells of all usual types including collecting duct cells (Meyrick and Reid, 1970). Occasionally a lymphoblast was identified but there was no evidence of $\overrightarrow{\overrightarrow{0}}$ lymphocytic or plasma cell infiltration. The blocks from alveolar tissue, although not as well preserved as the airway, showed that the alveolar structure was still intact (Fig. 2). The lining cells were usually the type II pneumonocyte (Fig. 3), the type I pneumonocyte being considerably less common. The type II cells contained lamellated bodies and were rather higher than usual. Generally the alveolar walls were thicker than normal, all structures contributing to this. The cytoplasm of the capillary endothelium was more electron dense than is normal. Platelet thrombi were present. Within some of the alveolar spaces there was fibrin and macrophages.

\section{COMMENT}

The cause of death was established as due to $\omega$ haemorrhage from perforation of the right upper ${ }^{\sigma}$ lobe pulmonary artery by an inflammatory necrotiz- $\stackrel{0}{c}$ ing process in the extrapulmonary part of the donor $\mathbb{D}$ bronchus. Inadequate vascularity to this area is ? believed to be a major contributing factor to this fatal event. There was little evidence of structural damage in the donor lung, the inflammatory process within $\stackrel{\odot}{\square}$ pulmonary tissue being relatively minor and prob- $\mathbb{\mathbb { Q }}$ ably representing very mild rejection. Obvious 


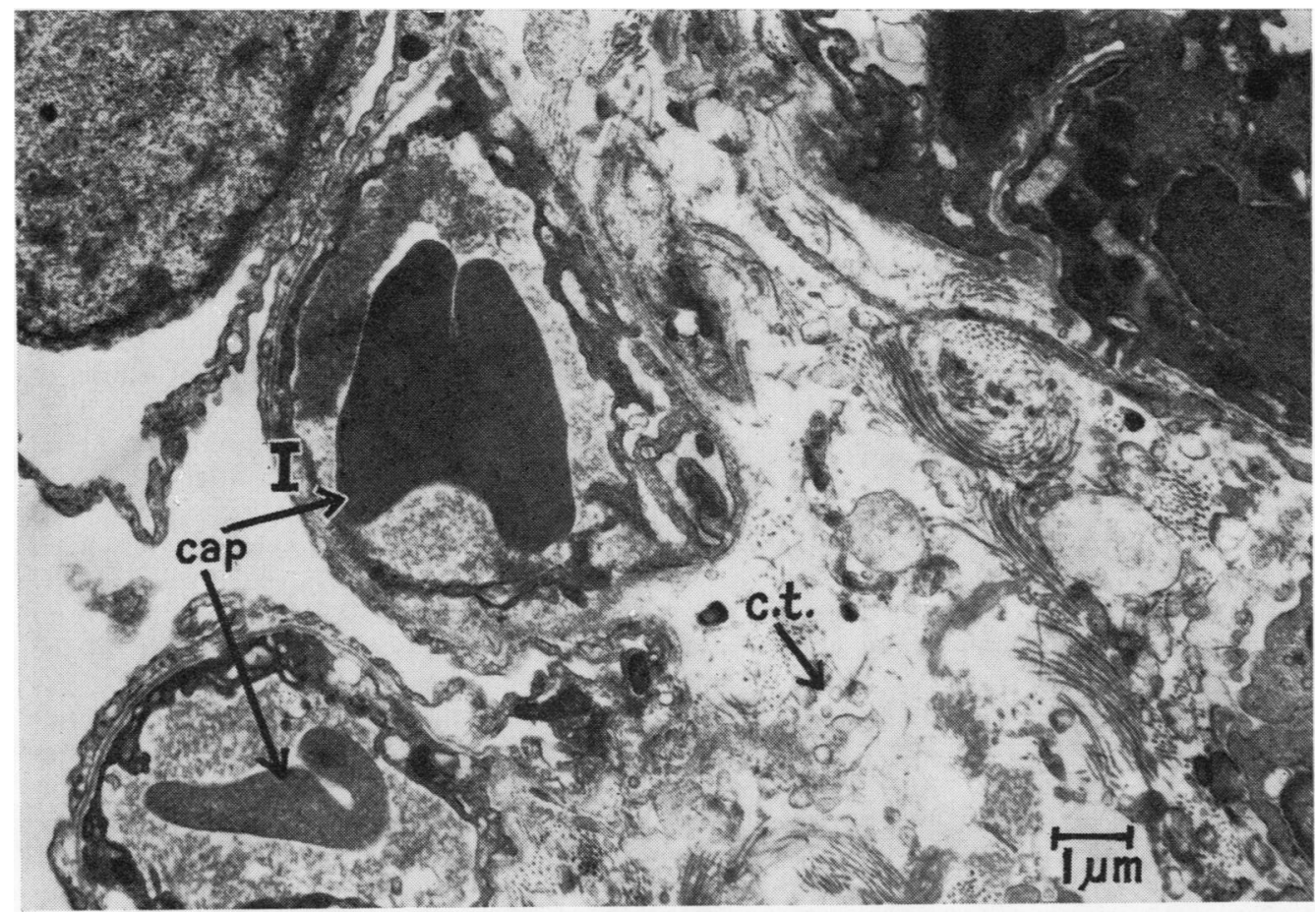

Fig. 2 Electron micrograph of the donor lung. Part of an alveolar wall showing two capillaries (cap) lined by dense endothelium and covered by a type I pneumonocyte (I). (c.t. = connective tissue around a blood vessel $)(\times 8,750)$.

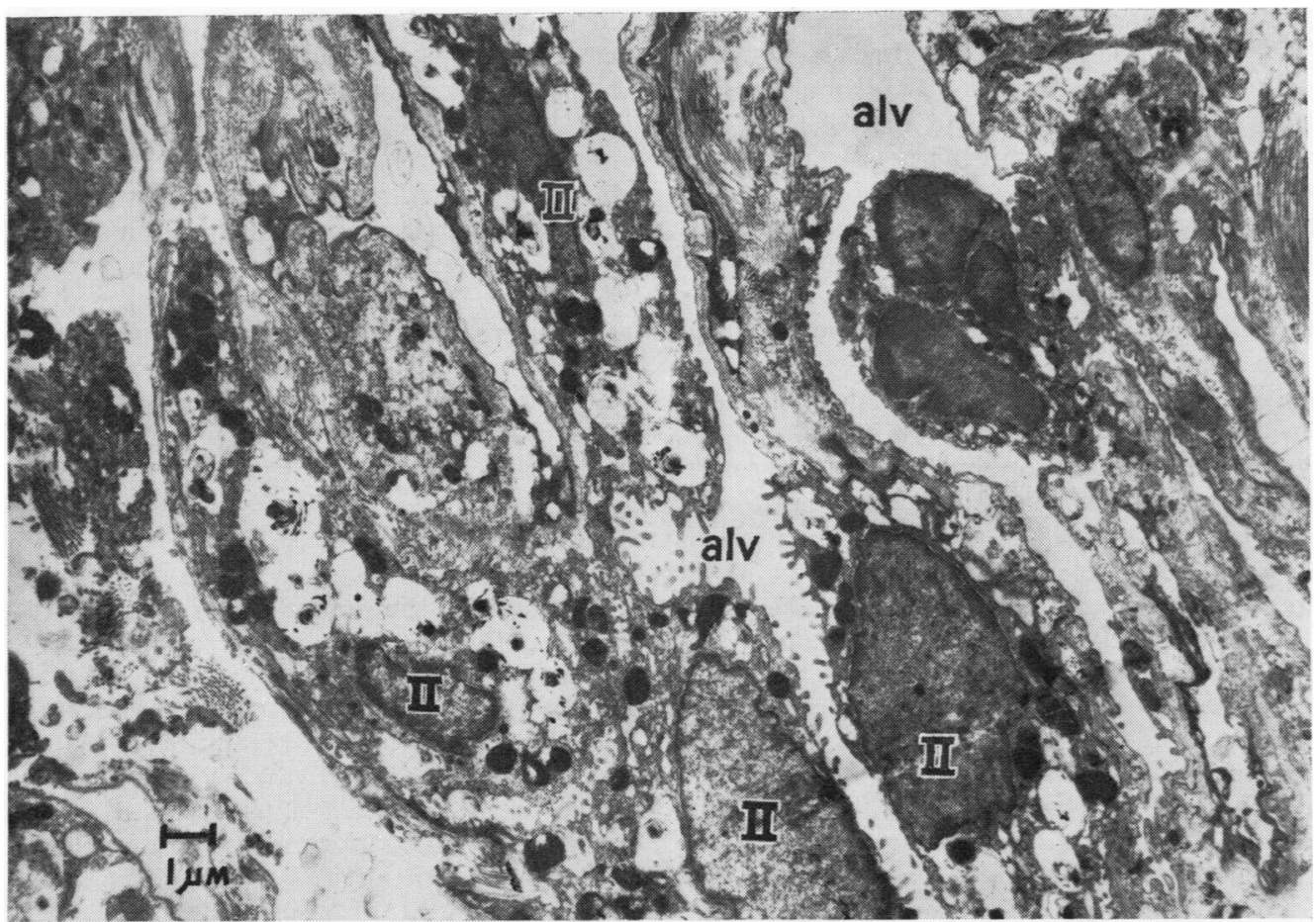

Fig. 3 Electron micrograph of the donor lung showing the relative increase in type II pneumonocytes (II) of which four are included $(\mathrm{alv}=$ alveolus $)(\times 5,250)$. 
current infection with acute inflammation was not present although some features, such as organizing fibrinous exudates, suggest the possibility of recent infective episodes. Cytomegalovirus was present. Electron microscopic changes were minor and as an increase in type II pneumonocytes is the usual response to alveolar damage, it may be regarded as non-specific, although it cannot altogether be ruled out that this represents the earliest detectable change of fibrosing alveolitis.

\section{Discussion}

Improvement of the blood supply to the bronchial donor stump remains one of the major unsolved problems in lung transplantation (Veith and Blumenstock, 1971). Of the 15 single human lung grafts analysed by Mills, Boyd, Gheranpong, and Spencer (1970), ulceration with or without disruption at or below the bronchial suture line occurred in 10 of the patients surviving for periods of less than one month, while in the longest survivor (Derom, Barbier, Ringoir, Versieck, Rolly, Berzsenyi, Vermeire, and Vrints, 1971) bronchial stenosis had developed. This avascularity would seem to be due to interference with blood supply and not to rejection of the allograft, since, in two of a series of eight patients treated for asthma by lung autotransplantation, fatal haemorrhage developed, due to fistula between the bronchus and pulmonary artery (Meshalkin, Sergeivsky, Feofilov, Savinsky, and Baeva, 1964). In a recent series of dog homografts, Mills et al (1970) sutured the bronchial artery of the recipient to that of the donor and improved the survival rate. They advocate that such anastomoses should also be attempted in human cases, but, because of technical difficulties, this is not at present a satisfactory solution and the possibility of other solutions needs to be explored.

Despite the accumulation of much knowledge concerning the bronchial arterial system, more detailed study is needed on the way arterial blood is distributed in the trachea and main bronchi. Notwithstanding, on the basis of present evidence, it seems justifieed to predict that the shorter the stump of the donor lung the greater is the chance that retrograde flow into the bronchial system from the pulmonary bed within the lung will maintain the vitality of tissues below the suture line. Huggins (1959) was able to show in reimplantation of the left lower lobe in the dog that, providing that 'the stump projected less than $1.0 \mathrm{~cm}$ from the lobe' collateral circulation was adequate whereas if it was $1.5 \mathrm{~cm}$ or over the airway became gangrenous.

Tissue rejection may be difficult although not impossible (Cullum, Bewick, Shilkin, Tee, Ayliffe, Hutchinson, Laws, Mason, Reid, Hugh-Jones, and
Macarthur, 1972) to diagnose either clinically or $\stackrel{\vec{\sigma}}{\vec{\sigma}}$ pathologically, even at necropsy. While this is one of the main problems of postoperative management, $\stackrel{\vec{O}}{+}$ the role of rejection in the impairment of lung $\bar{O}$ function and its contribution to the death of this and other lung-transplanted patients is still in $\frac{\bar{s}}{\vec{T}}$ doubt. Cell-mediated rejection, as manifested by $\stackrel{\mathbb{\Omega}}{\varrho}$ mononuclear cell infiltration of the donor lung, in has not been regarded as a significant cause of graft failure in many of the cases reported to date. Exudates of eosinophilic proteinaceous material $\vec{\omega}$ into the alveoli commonly occur after transplan- of tation and have been thought to have contributed $\overrightarrow{0}$ to the respiratory failure in some 11 cases. Such î exudate has been regarded as 'alveolar rejection' by Veith and Blumenstock (1971). Although there is no $\sigma$ ) proof as yet that this is so, recent analysis of the $\rightarrow$ ultrastructural changes in canine lung allografts $ᄋ$ (Gondos, White, and Benfield, 1971) suggest that endothelial and epithelial damage both occur within a day or so and are associated with the development of oedema. Therefore it may well be a non-specific $\stackrel{\oplus}{+}$ response and not necessarily a manifestation of $\vec{\varphi}$ rejection. As the sole cause of donor lung failure. N such an exudative process has been incriminated only once (Veith and Blumenstock, 1971). Neither cellular nor even this so-called 'alveolar rejection' was a major feature in the patient described here.

The good functional results in this patient were facilitated because he had a disease that prevented overdistension of the residual lung, so allowing favourable mechanical conditions to the donor lung immediately after transplantation. In 12 of the 23 cases summarized by Wildevuur and Benfield (1970) the residual lung was affected by chronic obstructive disease-probably emphysema. This would have the opposite effect to that of fibrotic lung disease in that 3 . the residual lung would tend to overinflate after $\delta$ transplantation and compress the donor lung. Such embarrassment to the donor lung in the early post- 음 operative period has been reported in at least five patients. In only two of the 23 cases was there a preoperative diagnosis of a primarily fibrosing disease, although in several others the residual lung o was probably not unduly distensible.

The question remains whether a donor lung will స్ట become affected by the underlying condition of ${ }^{\omega}$ fibrosing alveolitis. We would judge histologically that the changes in this patient's lungs suggested that the fibrosing alveolitis was cither subacute or $\stackrel{\mathscr{C}}{\rightarrow}$ 'burnt out' at the time of transplantation and also that after the seven weeks that the patient survived the donor lung did not seem significantly affected. The possibility of successful transplantation in this $\frac{\Omega}{\mathbb{D}}$ condition makes preoperative assessment of activity $\varrho$ of the disease process of considerable practical 
importance. The ESR is often very high in these cases (Livingstone et al, 1964) but, unfortunately, it was not assessed in the present patient in the months before operation. It would be of practical value to know more of the pattern of behaviour of such a test throughout the course of idiopathic fibrosing alveolitis and also to explore other features and tests that might offer a measure of activity. Nonetheless, the clinical course of this patient suggests that insofar as a lung transplantation is possible, terminal fibrosing alveolitis may prove to be one of the lung diseases best alleviated by the operation.

\section{References}

Cullum, P. A., Bewick, M., Shilkin, K., Tee, D. E. H., Ayliffe, P., Hutchinson, D. C. S., Laws, J. W., Mason, S. A., Reid, L., Hugh-Jones, P., and Macarthur, A. M. (1972). Distinction between infection and rejection in lung transplantation. Brit. med.J., 2, 71-74.

Derom, F., Barbier, F., Ringoir, S., Versieck, J., Rolly, G., Berzsenyi, G., Vermeire, P., and Vrints, L. (1971). Ten-month survival after lung homotransplantation in man. $J$. thorac. cardiovasc. Surg., 61, 835-846.

Fulton, R. M., Hutchinson, E. C., and Jones, A. M. (1952). Ventricular weight in cardiac hypertrophy. Brit. Heart J., 14, 413-420.
Gondos, B., White, P., and Benfield, J. R. (1971). Ultrastructural alterations in canine lung allografts. Amer. J. Path., 64, 373-386,

Hislop, A., and Reid, L. (1970). New pathological findings in emphysema of childhood: 1. Polyalveolar lobe with emphysema. Thorax, 25, 682-690.

Huggins, C. E. (1959). Reimplantation of lobes of the lung: an experimental technique. Lancet, 2, 1059-1062.

Hugh-Jones, P., Macarthur, A. M., Cullum, P. A., Mason, S. A., Crosbie, W. A., Hutchison, D. C. S., Winterton, M. C., Smith, A. P., Mason, B., and Smith, L. A. (1971). Lung transplantation in a patient with fibrosing alveolitis. Brit. med.J., 3, 391-398.

Livingstone, J. L., Lewis, J. G., Reid, L., and Jefferson, K. E. (1964). Diffuse interstitial pulmonary fibrosis: a clinical, radiological and pathological study based on $\mathbf{4 5}$ patients. Quart. J. Med., 33, 71-103.

Meshalkin, E. N., Sergievsky, V. S., Feofilov, G. L., Savinsky, G. A., and Baeva, A. V. (1964). First attempts at surgical treatment of bronchial asthma by the method of pulmonary autotransplantation. Eksp. Khir. Anest., 9 (6), 26-33.

Meyrick, B., and Reid, L. (1970). Ultrastructure of cells in the human bronchial submucosal glands. J. Anat. (Lond.), 107, 281-299.

Mills, N. L., Boyd, A. D., Gheranpong, C., and Spencer, F. C. (1970). The significance of bronchial circulation in lung transplantation. J. thorac. cardiovasc. Surg., 60, 866-878.

Veith, F. J., and Blumenstock, D. A. (1971). Lung transplantation. J. surg. Res., 11, 33-55.

Wildevuur, C. R. H., and Benfield, J. R. (1970). A review of 23 human lung transplantations by 20 surgeons. Ann. thorac. Surg., 9, 489-513. 